\title{
HASTANE İş GÜVENLİĞİ UYGULAMALARININ SAĞLIK ÇALIŞANLARININ İŞ GÜVENLİĞİ PERFORMANSINA ETKISİ
}

\author{
$* * *$ \\ EFFECTS OF HOSPITAL OCCUPATIONAL SAFETY PRACTICES ON \\ HEALTH WORKERS' OCCUPATIONAL SAFETY PERFORMANCE
}

\author{
Dr. Öğr. Üyesi Ahmet YILDIZ \\ Batman Üniversitesi \\ Sağllk Yüksekokulu \\ Sağlık Yönetimi Bölümü \\ ahmet.yildiz@batman.edu.tr \\ ORDIC: 0000-0001-8744-0225
}

\begin{abstract}
Öz
Bu çalışmanın amacı hastane iş güvenliği uygulamalarının sağlık çalışanlarının iş güvenliği performansına etkisini araştırmaktır. Çalışmada ayrıca iş güvenliği performansının çalışanların mesleki ve demografik özelliklerine göre fark gösterip göstermediği de araşttrllmıştır. Veri toplama aracı olarak "yönetim taahhüdü", "güvenlik eğitimi", "güvenlik iletişimi ve geri bildirim", "güvenlik kurallarl ve prosedürleri" ve "güvenlik tanttım politikaları" olmak üzere beş boyuttan oluşan Işs Güvenliği Uygulamaları Ölç̧eği ve İş Güvenliği Performans Ölçeği kullanılmıştır. Araşstırma 232 sağlık çalışanı üzerinde yapılmıştır. Araştırma sonucunda iş güvenliği uygulamaları boyutlarının tümü ile iş güvenliği performansı arasında istatistiksel olarak anlamlı ve pozitif bir iliş̧kinin olduğu ve iş güvenliği uygulamalarının iş güvenliği performansındaki değişimin \%65,9'unu açıkladı̆̆ı görülmüş̧ür. Ayrıca, yaşça büyük, meslekte çalışma süresi daha fazla ve gündüz görev yapan sağllk çalışanlarının iş güvenliği performanslarının daha yüksek olduğu görülmüş̧ı̈rr.
\end{abstract}

Anahtar Kelimeler: İ̧̧ Güvenliği Uygulamaları, İş Güvenliği Performansı, Sağlık Çalışanları, Hastaneler.

\begin{abstract}
The aim of this study is to investigate the effects of hospital occupational safety practices on occupational safety performance of healthcare professionals. In the study, it was also investigated whether the job safety performance differs according to the occupational and demographic variables of the employees. "Occupational Safety Practices Scale" including five dimensions as "management commitment", "safety training", "safety communication and feedback", "safety rules and procedures" and "safety promotion policies" and "Occupational Safety Performance Scale" used as data collection tool. The research was carried out on 232 healthcare professionals. As a result of the research, it was observed that there was a statistically significant and positive relationship between all the dimensions of occupational safety practices and occupational safety performance, and that occupational safety practices explained $65.9 \%$ of the change in occupational safety performance. In addition, it was observed that the job safety performance was higher on the health workers who are older, have a long working time and are working daytime.
\end{abstract}

Keywords: Occupational Safety Practices, Occupational Safety Performance, Healthcare Professionals, Hospitals. 


\section{GİRIŞ}

Ülkelerin gelişmişlik ve kalkınma göstergelerinden biri olan ve her geçen gün daha da önemli hale gelen iş sağlığ 1 ve güvenliği genel olarak çalışanların sağlık ve güvenliğini tehdit eden, iş ortamından kaynaklı risk ve tehlikelerin tanımlanması, değerlendirilmesi, kontrol edilmesi ve gerekli tedbirlerin alınması ile ilgili yapılan sistemli çalışmalar şeklinde tanımlanmaktadır (Alli, 2008: 8; Üngüren ve Koç, 2015: 126). Uluslararası Çalışma Örgütü (International Labour organization-ILO) ve Dünya Sağlık Örgütü (DSÖ) iş sağlığını; çalışanı işle ilgili tehlikelerden korumak, çalışanların fiziksel, ruhsal ve sosyal sağlık statüsünü yükseltmek, çalışan sağlığının bozulmasını engellemek, çalışanları yeteneklerine göre iş ortamına adapte etmek ve işin insana, insanın işe uyumunu sağlamak olarak tanımlamıştır (European Union, 2011: 14). İş sağlığı çalışanların sağlığını korunması ve yükseltilmesi olarak tanımlanırken, iş güvenliği, işin yapılması esnasında karşılaşılan risk ve tehlikelerin ortadan kaldırılması veya azaltılması ile ilgili, işverene getirilen yükümlülüklere ilişkin teknik kurallar bütünü olarak tanımlanmıştır (Çakar vd., 2012: 67; Maioh ve Faioh, 2007: 38; Yıldız, 2019: 5).

İş sağlığ ve güvenliği konusu, çalışma hayatının önemli sorunlarından birini teşkil etmektedir. ILO'ya göre, iş kazaları ve işe bağlı hastalıklar yüzünden yılda 2.78 milyon kişi hayatını kaybetmektedir. Ayrıca yılda 374 milyon kişi yaralanma ile sonuçlanan ve dört günden fazla işgöremez durumuna düşüren iş kazalarına maruz almaktadır. İş güvenliği uygulamalarının yetersizliği sonucu oluşan kayıpların ülkelerin gayri safi yurtiçi harcamalarının \%3,94'nü oluşturduğu tahmin edilmektedir (ILO, 2020).

İş sağlığ1 ve güvenliği bakımından önemli riskleri barındıran iş ortamlarından biri de sağlık hizmetlerinin sunulduğu ortamlar, özellikle hastanelerdir. Amerikan Ulusal Mesleki Sağlik ve Güvenlik Enstitüsü'ne (National Institute for Occupational Safety and Health - NIOSH) göre hastanelerde 29 çeşit fiziksel, 25 çeşit kimyasal, 24 çeşit biyolojik, 6 çeşit ergonomik ve 10 çeşit psiko-sosyal tehlike ve risk bulunmaktadır (Akt. Özkan ve Emiroğlu, 2006: 44). Amerika Birleşik Devletleri'ndeki (ABD) İş Güvenliğgi ve Sağlığı İdaresi (Occupational Safety and Health Administration-OSHA) hastanelerin en tehlikeli iş yerlerinden biri olduğunu belirtmiştir (OSHA, 2015). 2012 yılında yayımlanan İş Sağlığı ve Güvenliğine İlişkin İşyeri Tehlike Sınıfları Tebliği’nde de hastaneler "çok tehlikeli" iş yerleri sınıfında yer almıştır (Resmi Gazete, 2012).

İşgücü İstatistikleri Bürosuna (Bureau of Labor Statistics-BLS) göre 2014 y1lı itibariyle Amerika'da hastane çalışanlarının maruz kaldığı ölümcül olmayan iş kazası ve meslek hastalıklarının oranı tüm sektörlerde çalışanların maruz kaldığı ortalama iş kazası ve meslek hastalığı oranının yaklaşık iki katıdır. 2014 yılında, Amerika' da hastanelerde tam zamanlı olarak çalışan her 100 sağlık çalışanından 6,2'si iş kazasına uğramış ya da meslek hastalığına yakalanmıştır. İş günü kaybıyla sonuçlanan iş kazası ve meslek hastalıkları oranları incelendiğinde de hastane çalışanlarının iş günü kaybıyla sonuçlanan iş kazası ve meslek hastalıkları oranlarının diğer sektörlerin ortalamasından daha yüksek olduğu belirtilmiştir (Yıldız, 2019: 60-61). Yapılan araştırmalarda sağlık çalışanlarının çalışma ortamının güvenliğinin sağlanmamasından ötürü mekanik (bel, ekstremite, sırt ağrıları vb.), fiziki (iğne batması, gürültü vb.), kimyasal (dezenfektan, antiseptikler vb.), biyolojik (virüsler, mantarlar vb.), psikolojik (stres vb.) yaralanmalar ya da iş kazası yaşadığ 1 saptanmıştır. Ayrıca AIDS, hepatit gibi bulaşıcı hastalıklar, dermatit gibi cilt hastalıkları, varis gibi damar hastalıkları ve kanser gibi meslek hastalıklarından mağdur oldukları belirlenmiştir (Öztürk vd., 2012: 254).

Çalışanların maruz kaldıkları mesleki risk ve tehlikeler iş kazalarının artmasına, çalışan performansı ve veriminin düşmesine, ekonomik kayıplara ve sağlı çalışanlarının bakım verdiği kişilerin doğrudan risk altında kalmasına sebep olmaktadır. Bu nedenle, sağlık çalışanlarının çalışma ortamlarının sağlık koşullarına uygun hale getirilmesi, risk etmenlerinin ortadan kaldırılması gerekmektedir (Solmaz ve Solmaz, 2017: 148). Bu kapsamda, işletmelerin güvenlik politikalarını oluşturmaları, işletme içinde risk analizi yapmaları, organizasyon yapısını gözden geçirmeleri, her düzeyde çalışanların ihtiyaçlarını saptamaları, işletmede iş sağlı̆̆ ve güvenliği planını oluşturmaları, bu plan doğrultusunda hedefler ve yöntemler belirlemeleri gerekmektedir (Tüzüner ve Özaslan, 2011: 140). 
İş kazalarının nedenleri ile ilgili yapılan araştırmalarda iş kazalarının \%80'inin insana bağlı nedenlerden meydana geldiği ve çalışanların güvensiz davranışlarının iş kazalarına kaynaklık ettiği belirtilmiştir (Çakar vd., 2012: 40; Camkurt, 2013: 71; Sabuncuoğlu, 2013: 315; Yıldız, 2019: 26). Bu nedenle, iş sağlı̆̆1 ve güvenliğini sağlamak için alınması gereken önlemlerle birlikte çalışanların iş güvenliği performansının yükseltilmesi gerekmektedir. $\mathrm{Bu}$ çalışmanın amacı iş güvenliği uygulamalarının çalışanların iş güvenliği performansına etkisini araştırmaktır. Çalışmada ayrıca çalışanların iş güvenliği performansının mesleki ve demografik değişkenlere göre fark gösterip göstermediği de araştırılmıştır.

\section{KAVRAMSAL ÇERÇEVE}

\section{1. İş Güvenliği Performansı}

İş güvenliği performansı, güvenli iş ortamını sürdürmek ve iş yerinde güvenliği artırmak için çalışanların yerleşik güvenlik kurallarına ve prosedürlerine uyma eylemlerini ve ayrıca işyerinde genel güvenlik düzeyini sürdürmeye ve iyileştirmeye yardımcı olan çalışan davranışlarını içermektedir (Kapp, 2020: 1120). Güvenlikle ilgili davranışlar, kişilere fiziksel zarar verme olasılığını etkileyen herhangi bir işyeri davranışı olarak tanımlanmaktadır. Güvenli çalışma davranışı (örneğin, uyum, katılım) gelecekte zarar görme olasılığının azalması (yani güvenliğin varlığı) anlamına gelirken, güvensiz çalışma davranışı ister kasıtlı olsun ister kasıtsız olsun, gelecekte daha büyük bir zarar olasıllı̆g anlamına gelir (yani, güvenliğin olmaması) (Beus vd., 2016: 354). İş güvenliği performans1 çalışanların güvenli ve güvenli olmayan davranışlarının bir ölçüsü olarak ifade edilebilir. Güvenli olmayan davranış, bir çalışanın sistem güvenliğini olumsuz etkileyebilecek veya çalışanın kendisini veya iş arkadaşlarını tehlikeye atabilecek güvenlik kuralları, standartları, prosedürleri, talimatları ve sistemde belirtilen kriterleri dikkate almadan yaptığı herhangi bir davranış olarak tanımlanmaktadır. $\mathrm{Bu}$ tanıma göre, pek çok çalışmada vurgulanan iş kazalarında güvensiz davranış ön plana çıkan bir yere sahiptir (Mohammadfam vd., 2017: 35). Güvenli davranış kavramı ise güvenlik uyumu ve güvenlik katılımı davranışlarından oluşmaktadır. Güvenlik uyumu, güvenlik prosedürlerini takip etme, kişisel koruyucu ekipman kullanma ve güvenli bir makinede çalışma yapma gibi işyerinde minimum güvenlik standartlarını karşılamaya odaklanan davranışları ifade eder. Güvenlik katılımı, iş arkadaşlarına yardım etmek, işyerinde güvenlik programlarını teşvik etmek, gönüllü güvenlik faaliyetlerine katılmak, inisiyatif göstermek ve işyerinde güvenliği artırmak için çaba göstermek gibi kuruluşun bu alandaki amaç ve hedeflerini destekleyen davranışları ifade eder. Güvenlik uyumu çalışanların kişisel sağlığını ve güvenliğini iyileştiren davranışları içerirken, güvenlik katılımı organizasyonda genel güvenliği destekleyen davranışı içerir. Güvenlik uyumu, çalışanın iş rolünün bir parçası olarak kabul edilebilecek davranışları içerirken, güvenlik katılımı çalışanın resmi rolünün ötesindeki davranışlar, diğer bir deyişle örgütsel vatandaşlık davranışları da dahil olmak üzere daha büyük bir gönüllü unsuru içerir (Fernández-Muñiz vd., 2014: 296).

\section{2. İş Güvenliği Uygulamaları}

İş güvenliği uygulamaları çalışanlarının güvenliğini hedefleyen bir kuruluşun yönetimi tarafindan uygulanan veya takip edilen politikalar, stratejiler, prosedürler ve faaliyetlerdir. Genellikle toplam örgütsel yönetimin bir alt sistemi olarak kabul edilir ve çeşitli güvenlik yönetimi uygulamalarının yardımıyla örgütün güvenlik yönetimi sistemi aracılığıyla gerçekleştirilir. Güvenlik yönetimi sistemleri, örgüte entegre edilmiş ve çalışanların sağlı̆̆ını ve güvenliğini etkileyebilecek tehlikeleri kontrol etmek için tasarlanmış mekanizmalardır. Örgütte etkin bir emniyet yönetimine izin veren temel unsurlardır ve örgüt için geçerli olan mevcut mevzuata uyacak şekilde tasarlanmıştır. $\mathrm{Bu}$ uygulamaların bir organizasyonda ne ölçüde uygulandığı, yönetimin çeşitli eylemleri ve programları aracılığıyla ortaya çıkacak ve bir çalışan gibi içeriden biri tarafından açıkça görülecektir. Güvenlik yönetim sistemi (ve uygulamaları) örgütün güvenlik ikliminin öncüsü olarak kabul edilebilir (Vinodkumar ve Bhasi, 2010: 2083). Yönetim taahhüdü, güvenlik eğitimi, güvenlik iletişimi ve geribildirim, güvenlik kuralları ve prosedürleri ve güvenlik tanıtım politikaları güvenlik yönetiminin ve uygulamalarnın alt boyutları olarak değerlendirilmektedir. Aşağıda bu boyutların açıklamalarına yer verilmiştir. 


\subsubsection{Yönetim Taahhüdü}

Güvenliğe yönelik yönetim taahhüdü, çalışma ortamında güvenlik performansının belirleyici kilit bir faktörüdür. Güvenliğe yönelik yönetim taahhüdü, üst düzey yönetimin veya kuruluşların, çoğu zaman güvenlikle ilgili teşvik ve verilen çalışanları desteklemede gösterilen işyeri güvenliğini geliştirme taahhüdünü sergileme derecesidir. Üst düzey yönetimin bu taahhüdü, nihayetinde mümkün olduğunca güvenli bir şekilde çalışan çalışanların algısını şekillendirmeye yardımcı olur (Ashour vd., 2018: 29).

\subsubsection{Güvenlik Ĕ̈itimi}

Güvenlik eğitimi, genel organizasyonel başarıyı ve iş sağlığı ve güvenliği programlarının başarısını belirlemek için hayati bir araç olarak tanımlanmıştır. Güvenlik eğitimi, güvenlikle ilgili bilgi aktarımı ve bu şekilde edinilen bu bilginin, çalışanları mümkün olduğunca güvenli bir şekilde ve refahlarına maruz kalmadan nasıl çalıştırabileceği olarak tanımlanmaktadır. Güvenlik eğitimi çalışanların güvenlik davranışlarını şekillendirmenin gerçek bir yolu olduğu için, güvenlik eğitiminin güvenlik performansı sonuçlarını açıklamadaki gücü araştırmacılar tarafından vurgulanmıştır (Ashour vd., 2018: 28). Her başarılı organizasyonda, her başarılı kaza önleme programında ve herhangi bir iş sağlığ 1 ve güvenliği programında anahtar unsur, etkili güvenlik eğitimidir. Güvenlik eğitimi davranış becerilerini, ilgili bilgileri ve / veya tutumları geliştirir. Güvenlik eğitimi aynı zamanda kazaları daha öngörülebilir hale getirmek için araçlar sağlar. Tüm çalışanlar için güvenlik ve sağlık düzeyini iyileştirmek için, sistematik, kapsamlı bir güvenlik ve sağlık eğitimi programı oluşturmalıdır. Bu eğitim çalışanlar için bir rehber sağlamalıdır. Daha düşük kaza oranlarına sahip işletmelerin, çalışanlar için iyi bir güvenlik eğitimi ile karakterize edildiği belirlenmiştir. Bu nedenle, güvenlik eğitimi bir yönetim uygulaması olarak kabul edilir ve yeni işe alınan çalışanlar için eğitim, eğitim oturumlarında güvenlik konularının tartışılması, acil durumları karşılama eğitimi, eğitim programlarına katılmaya teşvik ve tehlike değerlendirme eğitimi ile ilgili öğeler güvenlik eğitimi kapsamında sağlanır (Vinodkumar ve Bhasi, 2010: 2084).

\subsubsection{Güvenlik Illetişimi ve Geri Bildirim}

Güvenlik iletişimi ve geri bildirim, işyerinde kazalarla sonuçlanan risk derecelerini belirlemek için bir organizasyonun güvenlik seviyesi hakkında bilgi ve veri sağlaması olarak tanımlanır. Güvenlik iletişimi ve geri bildiriminin önemi ve bunun işyeri güvenliği ile ilişkisi, çeşitli sektörlerde ve ülkelerde kanıtlanmıştır. Güvenlik iletişimi ve geri bildirim, örgütsel güvenlik uygulamaları, güvenlik uyumu, güvenlik katılımı ve örgütlerde daha düşük yaralanma ve kaza oranları ile ilgilidir. Güvenlik literatüründe, çalışanlar ve yönetim arasında uygun güvenlik iletişimi ve geri bildirimi ve düzenli iletişimin, yaralanma ve kazaların yüksek olduğu kurumlar ile az sayıda yaralanmanın olduğu kuruluşlar arasında ayrım yapan temel özellikler arasında olduğu kabul edilmiştir (Mashi vd., 2018: 2).

\subsubsection{Güvenlik Kuralları ve Prosedürleri}

Güvenlik kuralları ve prosedürleri, iş güvenliği ile ilgili bir olayın meydana gelmesinden önce oluşturulan ve sistem içinde faaliyet gösteren kişiye bir araç olarak empoze edilen ve / veya kabul edilen rutin ve tahmin edilen bir duruma yanıt olarak önceden belirlenmiş talimatlardır. Bir örgütteki herkes, üst yönetimin kendisine koyduğu güvenlik kurallarını kabul etmeli ve bunlara uymalıdır. Güvenlik kuralının amacı, bireysel davranışı belirlemek ve davranışı daha öngörülebilir hale getirmektir. Güvenlik kuralları ve prosedürleri çalışırken yapılabilecek ve yapılamayacak şeyleri belirterek insanların nasıl davrandığını kontrol eder. Çalışanarın işyerinde gerçekleştirebilecekleri eylemleri sınırlandırarak çalışanların güvensiz davranışlarını ortadan kaldırır (Hong vd., 2011: 22).

\subsubsection{Güvenlik Tanıtım Politikaları}

Güvenlik tanıtım politikaları, güvenlik yönetimi uygulamalarından biri olarak kabul edilmekte ve güvenli davranışın teşviki için olumlu bir faktör olarak sayılmaktadır. Güvenlik tanıtım politikaları, tehlikeleri bildirmek için ödül ve teşviklerin belirlenmesi, güvenlik haftası kutlamaları sırasında programlar düzenleyerek çalışanlar arasında farkındalık yaratılması, çalışanların güvenli olmayan koşulları veya eylemleri rapor etmelerinin sağlanması ve üstlerin, çalışanların güvenlik konularını 
rapor etmeye davet ve teşvik etmesi ile ilgili yönetim tarafından gerçekleştirilen uygulamalardan oluşmaktadır (Vinodkumar ve Bhasi, 2010: 2084).

\subsection{Araştırma Konusu ile İlgili Çalışmalar}

Stemn vd. (2019: 345) tarafından madenlerde çalıșan 828 kişi üzerinde yapılan bir çalıșmada güvenlik kültürü seviyesi yüksek olan madenlerde çalışan işçilerin diğer madenlerde çalışanlara göre güvenlik performansının daha yüksek olduğu görülmüştür. Chen vd. (2018: 434) tarafından inşaat sektöründe çalışan 431 kişi üzerinde yapılan bir çalışmada güvenlik iklimi, yönetim taahhüdü ve güvenlik bilincinin çalışanların güvenlik performansı üzerinde etkili olduğu belirlenmiştir. Chong vd. (2018: 179) tarafından imalat sektöründe faaliyet gösteren 105 kuruluşta yapılan bir çalışmada yönetim taahhüdü, çalışan katılımı ve güvenlik eğitiminin iç kontrolün uygulanması yoluyla güvenlik performansı ile ilişkili olduğu belirlenmiştir. İsmail (2020: 1) tarafindan küçük ve orta boyutlu işletmelerde çalışan 300 kişi üzerinde yapılan bir çalışmada iş güvenliği uygulamalarının (güvenlik eğitimi, güvenlik yönetim sistemleri, yönetim taahhüdü) çalışanların güvenlik performansının artırılmasında etkili olduğu belirlenmiştir. Ashour vd. (2018: 30) tarafından iş güvenliği uygulamaları ile güvenlik performansı arasındaki ilişkinin incelendiği bir çalışmada da güvenlik eğitimi ve yönetim taahhüdü değiş̧kenleri ile çalışanların güvenlik performasını arasında bir ilişki olduğu belirtilmiştir.

Çalışanların iş güvenliği performası ile güvenlik uygulamaları ilişkisini konu alan çalışmalar incelendiğinde çalışmaların daha çok inşaat ve imalat sektöründe çalışanlar üzerinde yapıldığ 1 ve sağlık sektöründe yapılan çalışmaların sınırlı olduğu görülmüş̧ür. Ayrıca iş güvenliği uygulamalarını bütünü ile ele alan çalışmalar sınırlıdır. Bu çalışma, mesleki risk ve tehlikelere en fazla maruz kalan meslek gruplarından biri olan sağlık çalışanları üzerinde yapılmıştır. Çalışmada, bütüncül bir yaklaşımla yönetim taahhüdü, geüvenlik eğitimi, güvenlik iletişimi ve geribildirim, güvenlik kuralları ve prosedürleri ve güvenlik tanıtım politikaları değişkenlerinin iş güvenliği performansı üzerindeki etkisi değerlendirilmiştir. Bu yüzden çalışma sonuçlarının bilimsel alana önemli katkısının olacağı düşünülmektedir.

\section{YÖNTEM}

\subsection{Veri Toplama Aracı}

Araştırmada, veri toplama aracı olarak kullanılan anket formunda, çalışanların iş güvenliği performanslarını ve iş güvenliği uygulamalarına ilişkin algılarını değerlendirmeye yönelik (Vinodkumar ve Bhasi, (2010) tarafından geliştirilmiş ölçekten yararlanılarak oluşturulmuş 33 madde ve çalışanların mesleki ve demografik özelliklerini belirmeye yönelik araştırmacı tarafından oluşturulmuş altı soru bulunmaktadır. İş güvenliği uygulamaları ölçeği "yönetim taahhüdü (8 madde)", güvenlik eğitimi (5 madde)", "güvenlik iletişimi ve geri bildirim (4 madde)", "güvenlik kuralları ve prosedürleri (4 madde)" ve "güvenlik tanıtım politikaları (4 madde)" olmak üzere beş boyuttan oluşmaktadır. İş güvenliği performansı ölçeği ise tek boyuttan (8 madde) oluşmaktadır. Ölçeklerin Türkçe uyarlaması araştırmacı tarafından yapılmıştır. Türkçe çeviri için aynı ölçeğin kullanıldığı Dursun (2013) tarafından yapılan çalışmadan da yararlanılmıştır. Yapısal geçerliliği sınamak için doğrulayıcı faktör analizi yapılmıştır. Ayrıca yakınsama ve ayrışma geçerliliği ile ölçeğin yapı geçerliliği sınanmıştır. Araştırmada kullanılan ölçekler 5'li Likert tipindedir (1=Kesinlikle katılmiyorum, 5=Kesinlikle kat1liyorum).

\subsection{Evren ve Örneklem}

Araştırma bir kamu hastanesinde görev yapan sağlık çalışanları (doktor, hemşire, acil tıp teknisyeni, laborant, ebe, röntgen teknisyeni) üzerinde yürütülmüştür. Araştırmaya katılmayı kabul eden tüm sağlık çalışanları (232 kişi) kapsama dahil edilmiştir. Anketler araştırmacı tarafından elden dağıtılarak uygulanmıştır. Anket uygulamada katılımcılardan onam alınmıştır. Ayrıca, T.C. Sağlık Bakanlığı Batman Bölge Devlet Hastanesi Etik Kurulu'ndan onay (Tarih: 14.11.2018, sayı: 122) alınmıştır.

\subsection{Verilerin Analizi}

Veriler, Statistical Package for the Social Sciences (SPPSS 21) ve Analysis of Moment Structures (AMOS) programı ile analiz edilmiştir. Araştırmada, yönetim taahhüdü, güvenlik eğitimi, güvenli 
iletişim ve geri bildirim, güvenlik kuralları ve prosedürleri ve güvenlik tanıtım politikaları bağımsız değişkenler; iş güvenliği performansı ise bağımlı değișken olarak ele alınmıştır. Değișkenler arasındaki ilişki Pearson Korelasyon analizi ile test edilmiştir. Bağımsız değişkenlerin bağımlı değişkenler üzerindeki etkisini değerlendirmek için ise Çoklu Doğrusal Regresyon Analizi yapılmıştır. Araştırmada katılımcıların mesleki ve demografik özellikleri ile ifadelere katılma durumları ortalama ve yüzde gibi betimleyici istatistiklerle değerlendirilmiştir. İş güvenliği performansının çalışanların mesleki ve demografik özelliklerine göre fark gösterip göstermediği iki ortalama arasındaki farkın önemlilik testi ( $\mathrm{t}$ test) ve tek yönlü varyans analizi (ANOVA) ile test edilmiştir. Parametrik testler için gerekli normallik varsayımının karşılanıp karşılanmadığı, değişkenlere ait basıklık ve çarpıklık değerleri incelenerek değerlendirilmiştir.

\section{BULGULAR}

\subsection{Katılımcılara Ait Tanımlayıcı Bulgular}

Katılımcıların yaklaşık üçte ikisi $(\% 63,4) 30$ yaş ve altındadır ve yarıdan fazlası $(\% 54,3)$ kadındır. Katılımcıların eğitim durumuna bakıldığında lisans mezunlarının ağırlıkta $(\% 43,5)$ olduğu görülmektedir. Araştırmaya katılanların önemli bir kısmı $(\% 59,5)$ hemşiredir. Katılımcıların yaklaşık yarısı $(\% 50,9)$ nöbet şeklinde görev yapmaktadır ve yarısından biraz fazlası $(\% 50,4) 5$ yıldan fazla kıdeme sahiptir (Tablo 1).

Tablo 1: Katılımc1ların Demografik Özellikleri

\begin{tabular}{|c|c|c|c|}
\hline & & $\mathbf{f}$ & $\%$ \\
\hline \multirow{2}{*}{ Yaş (Yll) } & $\leq 30$ & 147 & 63,4 \\
\hline & $>30$ & 85 & 36,6 \\
\hline \multirow{2}{*}{ Cinsiyet } & Erkek & 106 & 45,7 \\
\hline & Kadın & 126 & 54,3 \\
\hline \multirow{4}{*}{ Ĕ̆itim } & Sağlık Meslek Lisesi & 37 & 15,9 \\
\hline & Önlisans & 64 & 27,6 \\
\hline & Lisans & 101 & 43,5 \\
\hline & Lisansüstü & 30 & 12,9 \\
\hline \multirow{6}{*}{ Görev } & Doktor & 24 & 10,3 \\
\hline & Hemşire & 138 & 59,5 \\
\hline & Acil Tıp Teknisyeni & 33 & 14,2 \\
\hline & Laborant & 17 & 7,3 \\
\hline & Ebe & 13 & 5,6 \\
\hline & Röntgen Teknisyeni & 7 & 3,0 \\
\hline \multirow{3}{*}{ Çalışma Şekli } & Mesai & 47 & 20,3 \\
\hline & Nöbet & 118 & 50,9 \\
\hline & Mesai-Nöbet (Karışık) & 67 & 28,9 \\
\hline \multirow{2}{*}{ Meslekte Çalışma Süresi (Yıl) } & $\leq 5$ & 115 & 49,6 \\
\hline & $>5$ & 117 & 50,4 \\
\hline
\end{tabular}

\subsection{Değişkenlere Ait Tanımlayıcı Bulgular}

Normallik varsayımının karşılanıp karşılanmadığını belirlemek için her bir madde (soru) ve ayrıca her bir boyut için basıklık ve çarpıklık değerlerine bakılmıştır. Basıklık ve çarpıklık değerlerinin -1 ve +1 arasında olması verinin normal dağıldığını göstermektedir (Büyüköztürk, 2013). Bununla birlikte vasıklık ve çarpıklık değerlerinin -2 ve +2 arasında olması da normalden aşırı sapma olmadığı şeklinde değerlendirilmektedir (Şensoy ve Yıldırım, 2017: 38; Karasu ve Haşıloğlu, 2020: 145). Araştırmada her bir soru için bakılan basıklık ve çarpıklık değerlerinin -2 ve +2 değerleri arasında olduğu, her bir boyut için bakılan basıklık ve çarpıklık değerlerinin ise -1 ve +1 değerleri arasında olduğu görülmüsşür. Buna göre normakllik varsayımının karşılandığı söylenebilir.

Tablo 2 incelendiğinde; iş güvenliği uygulama alt boyutlarından puanı en yüksek boyutun güvenlik kuralları ve prosedürleri $(3,66 \pm 1,11)$ olduğu bunu sırasıyla yönetim taahhüdü $(3,58 \pm 1,17)$ güvenlik eğitimi $(3,51 \pm 1,22)$ ve güvenlik iletişimi ve geribildirim $(3,49 \pm 1,02)$ boyutlarının izlediği görülmektedir. Çalışanların iş güvenliği performans ortalamasının ise dörde yakın $(3,96 \pm 1,07)$ olduğu belirlenmiştir. 
Tablo 2: Değişkenlere Ait Tanımlayıcı Bulgular

\begin{tabular}{lcccc}
\hline Ölçek / Boyut & Ortalama & Standart Sapma & Basıklık & Çarpıklık \\
\hline Yönetim taahhüdü & 3,58 & 1,17 & $-0,470$ & $-0,724$ \\
\hline Güvenlik eğitimi & 3,51 & 1,22 & $-0,749$ & $-0,516$ \\
\hline Güvenlik iletişimi ve geribildirim & 3,49 & 1,02 & $-0,980$ & $-0,266$ \\
\hline Güvenlik kuralları ve rosedürleri & 3,66 & 1,11 & $-0,341$ & $-0,719$ \\
\hline Güvenlik tanıtım politikaları & 3,21 & 1,20 & $-0,596$ & $-0,270$ \\
\hline İș Güvenliği Performans1 & 3,96 & 1,07 & 0,164 & $-0,955$ \\
\hline
\end{tabular}

\subsection{Geçerlilik ve Güvenilirliğe İliş̧kin Bulgular}

Ölçeğin yapı geçerliliğini sınamak için ilk olarak yapılan doğrulayıcı faktör analizleri sonucunda bazı maddelerin faktör yüklerinin düşük olduğu görülmüştür. Yönetim taahhüdü boyutundan 2 madde, güvenlik eğitimi boyutundan 1 ve güvenlik tanıtım politikaları boyutundan 1 madde ölçekten çıkarılmıştır. Belirtilen maddeler çıkarıldıktan sonra yapılan doğrulayıcı faktör analizi sonucunda elde edilen uyum iyiliği indisleri ve uyum iyiliği İndeksleri için değerlendirme kriterleri Tablo 3'de sunulmuştur. Ölçeğe ilişkin uyum indisleri incelendiğinde, X2/sd $(2,39)$, RMSA $(0,078)$, CFI $(0,92)$ ve GFI'nın $(0,91)$ olduğu ve ölçeğin kabul edilebilir uyum düzeyinde olduğu görülmüştür (Gürbüz, 2019: 34).

Tablo 3: Doğrulayıcı Faktör Analizi Uyum İyiliği İndisleri

\begin{tabular}{ccccl}
\hline Uyum Ölçüsü & İyi Uyum & Kabul Edilebilir Uyum & Model & Uyum \\
\hline $\mathbf{X}^{2} / \mathbf{s d}$ & $<3$ & $3 \leq \mathrm{X}^{2} / \mathrm{sd} \leq 5$ & $861,52 / 360=2,39$ & Kabul edilebilir uyum \\
\hline RMSA & $0<0,05$ & $0,05 \leq \mathrm{RMSA} 0,08$ & 0,078 & Kabul edilebilir uyum \\
\hline CFI & $>0,90$ & $>0,95$ & 0,92 & Kabul edilebilir uyum \\
\hline GFI & $>0,90$ & $>0,95$ & 0,91 & Kabul edilebilir uyum \\
\hline
\end{tabular}

Ölçeklerin güvenirliği Cronbach Alfa katsayılarına bakılarak değerlendirilmiştir. Ölçek ve boyutlarına ilişkin Cronbach Alfa değerleri 0,82 - 0,95 arasında değişmektedir ve yüksek güvenilirliktedir. Ölçeğin yapı geçerliliğini sınamak için ayrıca yakınsama ve ayrışma geçerlikleri yapılmıştır. Yakınsama geçerliliğ̈i için standardize faktör yükleri kullanılarak AVE (Ortalama Açıklanan Varyans) değerleri hesaplanmıştır. AVE değerlerinin 0,50 'den büyük olması ölçeğin yakınsama geçerliliğine sahip olduğunu göstermektedir (Tablo 4).

Tablo 4: Değişkenlere İlişkin Cronbach Alfa ve AVE Değerleri

\begin{tabular}{lccc}
\hline Ölçek / Boyutlar & Madde Sayısı & Cronbach Alpha & AVE \\
\hline 1. Yönetim taahhüdü & 6 & 0,88 & 0,565 \\
\hline 2. Güvenlik eğitimi & 4 & 0,93 & 0,773 \\
\hline 3. Güvenlik iletişimi ve geribildirim & 4 & 0,95 & 0,832 \\
\hline 4. Güvenlik kuralları ve prosedürleri & 4 & 0,86 & 0,634 \\
\hline 5. Güvenlik tanıtım politikaları & 3 & 0,82 & 0,610 \\
\hline 6. İş Güvenliği Performansı & 8 & 0,86 & 0,720 \\
\hline
\end{tabular}

Ayrışma geçerliliği için ise AVE karekökü değerleri ile boyutlar arasındaki korelasyon katsayıları karşılaştırılmıştır. AVE karekök değerlerinin boyutlar arasındaki korelasyon katsayılarından büyük olması ölçeğin ayrışma geçerliliğine sahip olduğunu göstermektedir (Aktan, 2017: 146). AVE karekök değerlerinin boyutlar arasındaki korelasyon katsayılarından büyük olduğu görülmüş̧tür (Tablo 5). Buna göre ölçeğin yapı geçerliliğine sahip olduğu söylenebilir.

Tablo 5: Ayrışma Geçerliliği

\begin{tabular}{|c|c|c|c|c|c|c|}
\hline Boyutlar & 1 & 2 & 3 & 4 & 5 & 6 \\
\hline 1. Yönetim taahhüdü & 0,751 & & & & & \\
\hline 2. Güvenlik eğitimi & $0,641^{*}$ & 0,879 & & & & \\
\hline 3. Güvenlik iletişimi ve geribildirim & $0,615^{*}$ & $0,841 *$ & 0,911 & & & \\
\hline 4. Güvenlik kuralları ve prosedürleri & $0,727 *$ & $0,668^{*}$ & $0,614 *$ & 0,796 & & \\
\hline 5. Güvenlik tanıtım politikaları & $0,673^{*}$ & $0,615^{*}$ & $0,553 *$ & $0,792 *$ & 0,781 & \\
\hline 6. İş Güvenliği Performans1 & $0,713^{*}$ & $0,690^{*}$ & $0,662^{*}$ & $0,750^{*}$ & $0,596^{*}$ & $\mathbf{0 , 8 4 8}$ \\
\hline
\end{tabular}

Not: Koyu olan değerler değişkenlerin AVE değerlerinin karekökünü ifade etmektedir; ${ }^{*} \mathrm{p}<0,001$

Tablo 5'te iş güvenliği performansı ile iş güvenliği uygulamaları alt boyutları arasındaki korelasyon katsayıları gösterilmiştir. Korelasyon katsayısının mutlak değer olarak, 0,0 - 0,30 arasında 
olması düşük; $0,30-0,70$ arasında olması orta; $0,70-1,00$ arasında olması ise yüksek düzeyde bir ilişki olarak tanımlanmıştır (Büyüköztürk, 2013: 32). Buna göre iş güvenliği performansı ile güvenlik kuralları ve prosedürleri boyutu ve yönetim taahhüdü alt boyutları arasında pozitif yönlü, yüksek düzeyde (korelasyon katsayıları sırasıyla 0,750 ve 0,713 ) ve istatistiksel olarak anlamlı bir ilişki bulunmaktadır ( $\mathrm{p}<0,001)$. İş güvenliği performansı ile güvenlik eğitimi boyutu, güvenlik iletişimi ve geribildirim boyutu ve güvenlik tanıtım politikaları alt boyutları arasında ise pozitif yönlü, orta düzeyde (korelasyon katsayıları sirasıyla 0,690, 0,662 ve 0,596) ve istatistiksel olarak anlamlı bir ilişki bulunmaktadır $(\mathrm{p}<0,001)$.

Tablo 6: İş Güvenliği Uygulamalarının Çalışanların İş Güvenliği Performansına Etkisini Belirlemek Üzere Yapılan Çoklu Doğrusal Regresyon Analizi Sonuçları

\begin{tabular}{lcccccc}
\hline Değişkenler & B & S. Hata & $\boldsymbol{\beta}$ & $\mathbf{T}$ & $\mathbf{p}$ & VIF \\
\hline Sabit & 0,978 & 0,153 & - & 6,407 & 0,000 & \\
\hline Yönetim Taahhüdü & 0,213 & 0,059 & 0,233 & 3,592 & 0,000 & 2,782 \\
\hline Güvenlik Eğitimi & 0,164 & 0,068 & 0,186 & 2,392 & 0,018 & 3,990 \\
\hline Güvenlik İletişimi ve Geri bildirim & 0,137 & 0,065 & 0,154 & 2,103 & 0,037 & 3,532 \\
\hline Güvenlik Kuralları ve Prosedürleri & 0,416 & 0,074 & 0,433 & 5,586 & 0,000 & 3,972 \\
\hline Güvenlik Tanitım Politikaları & 0,105 & 0,067 & 0,103 & 1,575 & 0,117 & 2,814 \\
\hline
\end{tabular}

Bağımlı Değişken: İş Güvenliği Performansı; $F=87,312(p<0,001) ; R^{2}=0,659 ; R=0,812$

İş güvenliği uygulamalarının çalışanların iş güvenliği performansına etkisini belirlemek üzere yapılan çoklu doğrusal regresyon analizi sonuçları Tablo 6' da gösterilmiştir. Varyans Şişme Faktör (Variance Inflation Factor-VIF) katsayılarının 5'ten az olması çoklu bağlantı probleminin olmadığını göstermektedir. Bu çalışmadaki VIF değerleri 2,782 ile 3,990 arasında değişmektedir. Buna göre çoklu bağlantı problemlerinin olmadığ 1 söylenebilir. Kurulan regresyon modeli doğrusaldır ve model istatiksel olarak anlamlı bulunmuştur $(\mathrm{F}=32,850 ; \mathrm{p}<0,001)$. Bağımsız değişkenler olarak belirlenen yönetim taahhüdü, güvenlik eğitimi, güvenli iletişim ve geri bildirim, güvenlik kuralları ve prosedürleri ve güvenlik tanıtım politikaları değişkenlerinin bağımsız değişken olan iş güvenliği performansındaki değişimin \%65,9'unu açıkladığı görülmektedir. Standardize edilmiş regresyon katsayısına $(\beta)$ göre bağımsız değişkenlerin iş güvenliği performansı üzerindeki önem sırası; güvenlik kuralları ve prosedürleri, yönetim taahhüdü, güvenlik eğitimi, güvenlik iletişimi ve geri bildirim ve güvenlik tanıtım politikalarıdır. Regresyon katsayılarının anlamlılığına ilişkin t-testi sonuçları incelendiğinde güvenlik kuralları ve prosedürleri, güvenlik eğitimi, yönetim taahhüdü, güvenlik iletişimi ve geri bildirim değişkenlerinin iş güvenliği performansı üzerinde anlamlı bir etkiye sahip olduğu $(\mathrm{p}<0,05)$, güvenlik tanıtım politikaları değişkeninin ise iş güvenliği performansı üzerinde anlamlı bir etkiye sahip olmadığı görülmektedir $(\mathrm{p}>0,05)$.

Katılımcıların yaş, cinsiyet, görev ve meslekte çalışma süresi özelliklerine göre iş güvenliği performanslarının fark gösterip göstermediğini test etmek için $t$ testi yapılmış ve sonuçlar Tablo 7'de gösterilmiştir. Çalışanların iş güvenliği performansı yaş ve ve meslekte çalışma süresine göre anlamlı fark gösterirken $(\mathrm{p}<0,05)$; cinsiyet ve görev değişkenlerine göre ise iş güvenliği performansının anlamlı fark göstermediği $(\mathrm{p}>0,05)$ belirlenmiştir. 30 yaşından büyük çalışanların, 5 yıldan uzun süredir görev yapanların ve mesai şeklinde görev yapanların iş güvenliği performansı daha yüksek bulunmuştur. 
Tablo 7: Katılımcıların Yaş, Cinsiyet, Görev ve Meslekte Çalışma Süresi Özelliklerine Göre İş Güvenliği Performanslarının Karșılaștırılması

\begin{tabular}{|c|c|c|c|c|c|c|}
\hline Değișkenler & & $\mathrm{n}$ & Ort. $^{a}$ & $\mathbf{S S}^{\mathbf{b}}$ & $\mathrm{t}$ & p \\
\hline \multirow{2}{*}{ Yaş } & $\leq 30$ & 147 & 3,80 & 1,11 & \multirow{2}{*}{3,133} & \multirow{2}{*}{0,002} \\
\hline & $>30$ & 85 & 4,24 & 0,93 & & \\
\hline \multirow{2}{*}{ Cinsiyet } & Erkek & 106 & 3,91 & 1,07 & \multirow{2}{*}{0,670} & \multirow{2}{*}{0,504} \\
\hline & Kadın & 126 & 4,01 & 1,07 & & \\
\hline \multirow{2}{*}{$\begin{array}{l}\text { Meslekte Çalışma } \\
\text { Süresi }\end{array}$} & $\leq 5$ & 129 & 3,77 & 1,14 & \multirow{2}{*}{2,684} & \multirow{2}{*}{0,008} \\
\hline & $>5$ & 112 & 4,14 & 0,96 & & \\
\hline \multirow{2}{*}{ Görev } & Doktor & 24 & 3,95 & 1,09 & \multirow{2}{*}{0,172} & \multirow{2}{*}{0,864} \\
\hline & Diğerc $^{c}$ & 208 & 3,99 & 1,04 & & \\
\hline
\end{tabular}

a İş Güvenliği Performans Ortalaması, ${ }^{\mathrm{b} S t a n d a r t ~ S a p m a, ~}{ }^{\mathrm{c} H e k i m ~ D ı s ̧ ı ~ P e r s o n e l ~}$

Katılımcıların çalışma şekli ve eğitim özelliklerine göre iş güvenliği performanslarının fark gösterip göstermediğini test etmek için ANOVA testi yapılmış ve sonuçlar Tablo 8'de gösterilmiştir. Çalışanların iş güvenliği performansı çalışma şekline göre anlamlı fark gösterirken $(p<0,05)$; eğitim değiş̧kenine göre ise iş güvenliği performansının anlamlı fark göstermediği $(p>0,05)$ belirlenmiştir. Çalışma şekline göre farkın hangi gruplardan kaynaklandığını tespit etmek için önce varyansların homejen olup olmadığı test edilmiştir. Bunun için Levene testi yapılmıştır. Varyansların homejen olduğu $(p>0,05)$ belirlendikten sonra Tukey HSD testi yapılmıştır. Yapılan analiz sonucunda farkın mesai şeklinde görev yapanlar ile nöbet usulü çalışanlar arasında olduğu görülmüştür.

Tablo 8: Katılımcıların Çalışma Şekli ve Eğitim Özelliklerine Göre İş Güvenliği Performanslarının Karşılaștırılması

\begin{tabular}{|c|c|c|c|c|c|c|}
\hline Değişkenler & & $\mathrm{n}$ & Ort. $^{a}$ & $\mathbf{S S}^{\mathbf{b}}$ & $\mathbf{F}$ & $\mathbf{p}$ \\
\hline \multirow{4}{*}{ Eğitim } & Lise & 37 & 4,02 & 0,92 & \multirow{4}{*}{1,138} & \multirow{4}{*}{0,322} \\
\hline & Önlisans & 64 & 3,84 & 1,14 & & \\
\hline & Lisans & 101 & 4,05 & 1,06 & & \\
\hline & Lisansüstü & 30 & 4,11 & 1,05 & & \\
\hline \multirow{3}{*}{ Çalışma Şekli } & Mesai & 47 & 4,13 & 0,97 & \multirow{3}{*}{3,261} & \multirow{3}{*}{0,040} \\
\hline & Nöbet & 118 & 3,74 & 1,16 & & \\
\hline & Karma & 67 & 3,83 & 1,11 & & \\
\hline
\end{tabular}

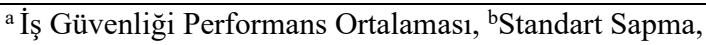

\section{TARTIŞMA}

Araştırmada yönetim taahhüdü, güvenlik eğitimi güvenlik iletişimi ve geri bildirim, güvenlik kuralları ve prosedürleri boyutlarının iş güvenliği performansını üzerinde anlamlı etkisinin olduğu görülmüştür. Yapılan farklı çalışmalarda da iş güvenliği uygulamalarının benzer şekilde iş güvenliği performansını etkilediği görülmüsşür (Dursun, 2013: 71; Vinodkumar ve Bhasi, 2010: 2090). Buna göre hastane yönetimin iş güvenliği konusunu önemsemesi, iş güvenliği konusunda çalışanlara kapsamlı ve etkili eğitim vermesi, çalışanları ile iş güvenliği konusunda etkili iletişim sağlaması ve geri bildirimde bulunması, uygun güvenlik prosedür ve kuralları belirlemesi ve bunlara uyulması ile ilgili gerekli denetim ve takip faaliyetlerini yürütmesi ve çalışanların güvenli davranışlarının takdir edilmesi ile çalışanların iş güvenliği performansının artacağı söylenebilir. Esasen yukarıda ele alınan iş güvenliği uygulamalarının uygun bir güvenlik iklimi ve güvenlik kültürü oluşturulmasında da etkili olabileceği söylenebilir. Yapılan araştırmalarda güvenlik kültürünün oluşturulmasında üst yönetim uygulamalarının önemli rolü olduğu belirtilmiştir (Ardahan ve Yelkin Alp, 2015: 87; Şerifoğlu ve Sungur, 2007: 16-17). Uygun güvenlik iklimi ve güvenlik kültürünün oluşturulması da iş güvenliğinin sağlanmasında önemli yararlar sağlamaktadır (Arpat, 2018: 292-293).

Araştırmada iş güvenliği performansı üzerinde en fazla etkili olan değişkenin güvenlik kuralları ve presedürleri olduğu görülmüştür. Buna göre hastanede takip edilen güvenlik kuralları ve prosedürlerinin iş kazalarını önlemek için yeterli olmasının, yöneticilerim her zaman güvenli çalışma prosedürlerini uygulamaya çalışmasının, güvenlik denetimlerinin düzenli olarak gerçekleştirilmesinin ve çalışanların hastaneden uygulanan güvenlik prosedürleri ve uygulamalarının faydalı ve etkili olduğuna inanmasının çalışanların iş güvenliği performansını artırdığı söylenebilir. Hong vd. (2011) de güvenlik kuralları ve prosedürlerinin çalışanların iş yerinde neleri yapıp neleri yapacağını ortaya 
koyarak çalışanların güvensiz davranışlarını önlediğini ve çalışanların iş güvenliğne dair performansını artırdığını belirtmiştir.

Araştırmada meslekte çalışma süresi fazla olan ve yaşça daha büyük olan çalışanların iş güvenliği performansının daha yüksek olduğu görülmüştür. Meslekte çalışma süresi daha fazla ve yaşça daha büyük çalışanların mesleki tecrübelerinin daha fazla olması, yönetim tarafından kendilerine daha fazla sorumluluk verilmesi, daha az kıdeme sahip çalışanlara karşı kendilerini örnek davranış göstermek zorunda hissetmesi ve çeşitli yaşantı ve deneyimler yoluyla güvenli davranışların önemini daha iyi kavramaları nedeniyle iş güvenliği performanslarının daha yüksek olduğu söylenebilir.

Araştırmada çalışanların iş güvenliği performanslarının çalışma şekline göre anlamlı fark gösterdiği ve sadece gündüz çalışanların iş güvenliği performanslarının daha yüksek olduğu görülmüştür. Vardiyalı ya da nöbet şeklinde çalışanların uyku düzenin bozulması ve daha uzun çalışma süresi olduğundan yorgunluk dikkat eksikliği oluşması nedeniyle iş güvenliği performansının düşük olduğu söylenebilir. Özvurmaz ve Öncü, (2018) 290 hemşire üzerinde yapılan bir çalışmada da benzer şekilde vardiya ve nöbet şeklinde çalışan hemşirelerin daha fazla uyku düzeni bozukluğu, iş performansında azalma ve dikkat eksikliği/konsantrasyon sorunu yaşadığı belirlenmiştir.

Araşırma sonuçları araştırmaya katılan çalışanların değerlendirmeleriyle sınırlıdır. Araştırma sonuçlarının genellenebilmesi için araştırma kapsamının genişletilerek araştırmanın başka hastanelerde ve başka çalışanlar üzerinde de yapılması önerilmektedir.

\section{SONUÇ}

Hastane yönetimi iş güvenliği uygulamalarının çalışanların iş güvenliği performansına etkisinin değerlendirildiği bu çalışmada yönetim taahhüdü, güvenlik eğitimi, güvenli iletişim ve geri bildirim, güvenlik kuralları ve prosedürleri ve güvenlik tanıtım politikaları boyutlarından oluşan iş güvenliği uygulamaları ile çalışanların iş güvenliği performansı arasında istatiksel olarak anlamlı ve pozitif bir ilişkinin olduğu ve iş güvenliği uygulamalarının iş güvenliği performansındaki değişimin \%65,9'unu açıkladığı görülmüştür. Çalışmada ayrıca iş güvenliği performansının mesleki ve demografik değişkenlere göre fark gösterip göstermediği de araştırılmış ve iş güvenliği performansının yaş, meslekte çalışma süresi ve çalışma şekli değişkenlerine anlamlı fark gösterdiği görülmüştür.

İnsanlar zamanlarının önemli bir kısmını iş ortamında geçirirler. İş ortamında geçirilen süre içinde de çok sayıda mesleki risk ve tehlike ile karşılaşırlar. Hastaneler mesleki risk ve tehlikelere en çok maruz kalınan iş ortamlarıdır. Sağlık çalışanları bir yandan hastaların sağlığına kavuşması için çabalarken diğer yandan kendilerinin sağlığını kaybetme riski ile karşı karşıya kalırlar. İş kazaları ve meslek hastalıklarının en önemli nedenleri arasında çalışanların güvensiz davranışları gösterilmektedir. Bu bakımdan çalışanların iş güvenliği performanslarının artırılması için çalışmaların yapılması gerekmektedir. İş kazalarının nedenleri arasında ilk sırada çalışanların güvensiz davranışları gösterilmektedir. Bu çalışma sonucunda iş güvenliği uygulamalarının sağlık çalışanlarının iş güvenliği performansını artırdığ 1 görülmüştür. $\mathrm{Bu}$ yüzden hastane yönetiminin güvenlik konusuna öncelik vermesi, güvenlik kuralları ve prosedürlerinin uygulanmasını sağlaması ve takip etmesi, koruyucu ekipman sağlaması, iş kazaları ve tıbbi hataları raporlamayı teşvik etmesi, iş güvenliği konusunda açık iletişimi geliştirmesi, çalışanlara kapsamlı, yeterli ve etkili iş güvenliği eğitimi sağlaması, güvenli davranışları özendirmesi, güvenli olmayan davranış veya durumların bildirilmesi ve uygun güvenlik politikalarının oluşturulması gibi hastane uygulamalarının çalışanların iş güvenliği kural ve prosedürlerine uyumunu ve güvenlik ile ilgili çalışmalara katılımını artırmak suretiyle iş güvenliği performansını artıracağı ve iş kazaları ve meslek hastalıklarını azaltabileceği söylenebilir.

Etik Beyanı: Bu çalışma için T.C. Sağllk Bakanlığı Batman Bölge Devlet Hastanesi Etik Kurulu'ndan ilgili kurulun 14.11.2018 tarihli ve 122 sayll karart ile izin alınmıştır. Aksi bir durumun tespiti halinde tüm sorumluluk yazar(lar)a aittir. 


\section{KAYNAKÇA}

AKTAN, M. (2017). "Ülke Kişiliği Ölçeğinin Türkçe Uyarlamasının Güvenilirliği ve Geçerliliği". Marmara Üniversitesi Öneri Dergisi, 12(7): 133-153.

ALLI, B. O. (2008). Fundamental Principles of Occupational Health and Safety (Second Edition). Geneva: International Labour Organization Publications.

ASHOUR, A. M., HASSAN, Z. ve ALEKAM J. M. E. (2018). "A Conceptual Framework for Upgrading Safety Performance by Influence Safety Training", Management Commitment to Safety and Work Environment: Jordanian Hospitals. International Journal of Business and Social Research, 8(7): 25-35.

ARPAT, B. (2018). "Üst Yönetimin İş Güvenliği Bağl1lığını Açıklayan Değişkenlerin Güvenlik Kültürü Çerçevesinde İncelenmesi: Denizli Büyükşehir Belediyesi Örneği". Yönetim ve Ekonomi Araştırmaları Dergisi, 16(1): 290-313.

ARDAHAN, M. ve YELKİN ALP, F. (2015). "Hasta Güvenliği ve Hasta Güvenliğini Sağlamada Sağlık Çalışanlarının ve Yöneticilerin Rolü". Acıbadem Üniversitesi Sağlık Bilimleri Dergisi, 6(2): $85-88$.

BEUS, J. M., MCCORD, M. A. ve ZOHAR, D. (2016). "Workplace Safety: A Review and Research Synthesis". Organizational Psychology Review, 6(4): 352-381.

BÜYÜKÖZTÜRK, Ş. (2013). Sosyal Bilimler İçin Veri Analizi El Kitabı (18. Baskı). Ankara: Pegem Akademi.

CHEN, Y., MCCABE, B. ve HYATT, D. (2018). "A Resilience Safety Climate Model Predicting Construction Safety Performance". Safety Science, 109: 434-445.

CHONG, H. C., RAMAYAH, T. ve SUBRAMANIAM, C. (2018). "The Relationship Between Critical Success Factors, Internal Control and Safety Performance in the Malaysian Manufacturing Sector". Safety Science, 104: 179-188.

ÇAKAR, A. E., AKBABA, T., YAZICI, M., TEKİN, B. ve ÇAKAR, Y. (2012). İşçi Sağlığı ve İş Güvenliği Oda Raporu (4. Baskı). Ankara: Ankamat Matbaacılık.

CAMKURT, M. Z. (2013). "Çalışanların Kişisel Özelliklerinin İş Kazalarının Meydana Gelmesi Üzerindeki Etkisi". TÜHİS İş Hukuku ve İktisat Dergisi, 24(6): 70-101.

DURSUN, S. (2013). "İş Güvenliği Kültürünün Çalışanların Güvenli Davranışları Üzerine Etkisi". Sosyal Güvenlik Dergisi, 3(2): 61-75.

EUROPEAN UNION. (2011). Occupational Health and Safety Risks in the Healthcare Sector Guide to Prevention and Good Practice. Publications Office of the European Union.

FERNÁNDEZ-MUÑIZ, B., MONTES-PEÓN, J. M. ve VÁZQUEZ-ORDÁS, C. J. (2014). "Safety Leadership, Risk Management and Safety Performance in Spanish Firms". Safety Science, 70: 295-307.

GÜRBÜZ, S. (2019). AMOS ile Yapısal Eşitlik Modellemesi. Ankara: Seçkin Yayıncılık.

HONG, K. T., SURIENTY, L. ve HUNG, D. K. M. (2011). "Safety Management Practices and Safety Behaviour: A Preliminary Investigation in Malaysian Small And Medium Enterprises in Northern Corridor Economic Region (NCER)". Journal Occupational Safety \& Health, 8: 111.

INTERNATIONAL LABOUR ORGANIZATION. (2020). "Safety and Health at Work." [https://www.ilo.org/global/topics/safety-and-health-at-work/lang--en/index.htm]. (18.03.2020).

ISMAİL, N. N. H. (2020). "Employees' Perceptions Towards the Relationship between Safety Management Practices and Safety Performance of Smes Industry in Kelantan". International Journal of Entrepreneurship and Management Practices, 3 (11): 01-09. 
KAPP, E. A. (2012). "The Influence of Supervisor Leadership Practices and Perceived Group Safety Climate on Employee Safety Performance". Safety Science, 50(4): 1119-1124.

KARASU, İ. ve HAŞILOĞLU, M. A. (2019). "Okuduğunu Anlama Yorumlama ve Dört İşlem Becerisinin 6. Sınıf Fen Bilimleri Dersi Sürat Konusundaki Öğrenci Başarısına Etkisi". Journal of Computer and Education Research, 8(15): 136-155.

MASHI, M. S., SUBRAMANIAM, C. ve JOHARI, J. (2018). "The Effect of Management Commitment to Safety, and Safety Communication and Feedback on Safety Behavior of Nurses: The Moderating Role of Consideration of Future Safety Consequences". The International Journal of Human Resource Management, 1-30.

MAIOH, J. D. ve FAIOH, G. D. (2007). Occupational Health, Basic Toxicology and Epidemiology (C. Tillman (Ed.); pp. 33-59). Ligare Book Printer.

MOHAMMADFAM, I., GHASEMI, F., KALATPOUR, O. ve MOGHIMBEİGI, A. (2017). Constructing a Bayesian Network Model for Improving Safety Behavior of Employees at Workplaces. Applied Ergonomics, 58: 35-47.

OCCUPATIONAL SAFETY AND HEALTH ADMINISTRATION. (2015). "Worker Safety in Your Hospital". (15.03.2019).

ÖZKAN, Ö. ve EMİROĞLU, N. (2006). "Hastane Sağlık Çalışanlarına Yönelik İşçi Sağlı̆̆ı ve İş Güvenliği Hizmetleri". CU Hemşirelik Yüksekokulu Dergisi, 10(3): 43-51.

ÖZTÜRK, H., BABACAN, E. ve ANAHAR ÖZDAŞ, E. (2012). "Hastanede Çalısan Sağllk Personelinin İ Ş Güvenliği". Gümüşhane Üniversitesi Sağllk Bilimleri Dergisi, 1(4): 252-268.

ÖZVURMAZ, S. ve ÖNCÜ, A. Z. (2018). "Vardiyalı ve Nöbet Sistemi Şeklinde Çalışma Düzeninin Hemşireler Üzerine Etkisi". Adnan Menderes Üniversitesi Sağlık Bilimleri Fakültesi Dergisi, 2(1): 39-46.

RESMİ GAZETE. (2012). İş Sağlığ1 ve Güvenliğine İlişkin İşyeri Tehlike Sınıfları Tebliği, No: 28509, 26 Aralık 2012.

SABUNCUOĞLU, Z. (2013). İnsan Kaynakları Yönetimi. İstanbul: Beta Basım.

SOLMAZ, M. ve SOLMAZ, T. (2017). "Hastanelerde İş Sağlığ1 ve Güvenliği". Gümüşhane Üniversitesi Sağlık Bilimleri Dergisi, 6(3): 147-156.

STEMN, E., BOFINGER, C., CLIFF, D. ve HASSALL, M. E. (2019). "Examining the Relationship Between Safety Culture Maturity and Safety Performance of The Mining Industry". Safety Science, 113: 345-355.

ŞENSOY, Ö. ve YILDIRIM, H. İ. (2017). "Araştırma Soruşturma Tabanlı Öğrenme Yaklaşımının Yaratıcı Düşünme ve Bilimsel Süreç Becerilerine Etkisi". Cumhuriyet International Journal of Education, 6(1): 34-46.

ŞERIFOĞLU, E. K. ve SUNGUR, E. (2007). "İşletmelerde Sağlık ve Güvenlik Kültürünün Oluşturulması; Tepe Yönetimin Rolü ve Kurum İçi İletişim Olanaklarının Kullanımı". İstanbul Üniversitesi İşletme İktisadı Enstitüsü Yönetim Dergisi, 58(18): 2-17.

TÜZÜNER, V. L. ve ÖZASLAN, B. Ö. (2011). "Hastanelerde İş Sağlığ1 ve Güvenliği Uygulamalarının Değerlendirilmesine Yönelik Bir Araştırma". İstanbul Üniversitesi İşletme Fakültesi Dergisi, 40(2): 138-154.

ÜNGÜREN, E. ve KOÇ, S. (2015). "İş Sağlığ1 ve Güvenliği Uygulamaları Performans Değerlendirme Ölçeği: Geçerlik ve Güvenirlik Çalışması", Occupational Health and Safety Application Performance. Sosyal Güvenlik Dergisi, 5(2): 124-144. 
VINODKUMAR, M. N. ve BHASI, M. (2010). "Safety Management Practices and Safety Behaviour: Assessing the Mediating Role of Safety Knowledge and Motivation". Accident Analysis and Prevention, 42(6): 2082-2093.

YILDIZ, A. (2019). Hastanelerde İş Sağlığı ve Güvenliği. Bursa: Ekin Kitabevi Yayınları. 